\title{
Diagnóstico diferencial en pacientes con granulomas en biopsias de pulmón, pleura y/o ganglios mediastínicos del Instituto Nacional del Tórax
}

\author{
ANGÉLICA BELLO F.*, FRANCISCO ARANCIBIA H.**, FERNANDA CORVALÁN S.*, \\ HUGO VALENZUELA C.**, CRISTINA FERNÁNDEZ F.*** y SYLVIA CHANDÍA B.***
}

\section{Differential diagnosis in patients with granulomas in the biopsy of the lung, pleura and/or mediastinal nodes}

Granulomatous diseases comprise a wide range of pathologies. However, in clinical practice, many pulmonary granulomas remain without etiology after the histologic examination. Our aim was to determine from the biopsies of the lung, pleura and mediastinal lymph nodes in which granulomas were reported, the clinical characteristics and diagnoses of the patients. Methodology: We analyzed retrospectively biopsies of the lung, pleura and mediastinal lymph nodes with granulomas from 75 patients handled at our institution (2012-2016), as well as their clinical and laboratory data. The information was obtained from medical records. A one-year mortality date was obtained from the civil registry. Main results: A cause was determined in all the cases, except in three of them (4\%). The most frequent diagnoses were tuberculosis $(n=37 ; 49 \%)$ and sarcoidosis $(n=18 ; 24 \%)$. Other causes were silicosis (5.3\%), vasculitis (4\%) and hypersensitivity pneumonitis (2.7\%). Patients with tuberculosis (TB) had higher inflammatory parameters such as erythrocyte sedimentation rate and $C$-reactive protein. Besides granulomas with caseous necrosis were only found in TB patients. Instead, patients with sarcoidosis had skin lesions and a higher frequency of lymphadenopathy. Four patients (5.3\%) died in a one-year of follow-up: two of them because of pneumonia and the other two patients because of chronic hypersensitivity and TB respectively. Conclusion: Tuberculosis and sarcoidosis were the most common causes of respiratory granulomas in this retrospective study. A specific cause was determined in $96 \%$ of cases, considering clinical, laboratory and histopathological variables to do a right differential diagnosis.

Key words: Granuloma; Tuberculosis; Sarcoidosis; Biopsy; Differential diagnosis.

\section{Resumen}

Las enfermedades granulomatosas incluyen una amplia gama de enfermedades. Sin embargo, en la práctica clínica, muchos casos de enfermedad granulomatosa permanecen sin etiología después del examen histológico. Nuestro objetivo fue determinar, a partir de las biopsias de pulmón, pleura y ganglios linfáticos mediastínicos, en los que se informaron granulomas, las características clínicas y los diagnósticos de estos pacientes. Así también la mortalidad a un año de seguimiento. Metodología: Analizamos retrospectivamente biopsias de pulmón, pleura y/o ganglios linfáticos mediastínicos con granulomas de 75 pacientes del Instituto Nacional del Tórax (2012-2016), sus características clínicas y de laboratorio. La información se obtuvo de los registros médicos. Los datos de mortalidad se obtuvieron del registro civil. Resultados: Se determinó una etiología en todos los casos, excepto en 3 (4\%). Los diagnósticos más frecuentes fueron tuberculosis $(n=37 ; 49 \%)$ y sarcoidosis $(n=18 ; 24 \%)$. Otras causas fueron silicosis (5,3\%), vasculitis (4\%) y neumonitis por hipersensibilidad (2,7\%). Los pacientes con tuberculosis (TB) tenían parámetros inflamatorios más altos, como velocidad de eritrosedimentación y proteína C reactiva. Además, sólo se encontraron granulomas con necrosis caseosa

\footnotetext{
* Becarios del Programa de Enfermedades Respiratorias del Adulto. Universidad de Chile - Instituto Nacional del Tórax. Santiago, Chile.

** Broncopulmonar Adulto. Servicio de Medicina Instituto Nacional del Tórax. Santiago, Chile.

*** Anatomopatóloga. Servicio de Anatomía Patológica Instituto Nacional del Tórax. Santiago, Chile.
} 
en pacientes con tuberculosis. En cambio, los pacientes con sarcoidosis tenían lesiones cutáneas y una mayor frecuencia de linfadenopatías. Cuatro (5.3\%) pacientes fallecieron a un año de seguimiento: dos debido a neumonía, uno por hipersensibilidad crónica y uno por TB. Conclusión: La tuberculosis y la sarcoidosis fueron las causas más frecuentes de granulomas respiratorios en este estudio retrospectivo. Se logró determinar una etiología en el $96 \%$ de los casos, considerando variables clínicas, de laboratorio e histopatológicas para un diagnóstico diferencial correcto.

Palabras clave: Granulomas; Tuberculosis; Sarcoidosis; Biopsia; Diagnóstico diferencial.

\section{Introducción}

Para el clínico, el tener una biopsia del sistema respiratorio y/o ganglios linfáticos mediastínicos en que se informa presencia de granulomas lo enfrenta a una serie de diagnósticos posibles cuyos tratamientos pueden ser completamente opuestos entre sí. La etiología puede ser infecciosa o una enfermedad inflamatoria que pudiera requerir inmunosupresión, lo que plantea un gran desafío donde es importante conjugar los antecedentes clínicos, el modo de presentación, los exámenes de laboratorio, imágenes y el tipo de granuloma encontrado para tomar la mejor decisión.

El granuloma corresponde a una agregación focal de células inflamatorias, macrófagos activados (histiocitos epitelioídeos), células gigantes de Langerhans y linfocitos. La presencia de necrosis, linfocitos, células plasmáticas o células gigantes multinucleadas no son esenciales para la formación del granuloma. La necrosis caseificante es definida como una región del granuloma con necrosis eosinofílica, granular y detritos celulares ${ }^{1}$.

El grupo de enfermedades pulmonares capaces de producir granulomas es heterogéneo, pudiendo dividirse en causas infecciosas y no infecciosas. Las manifestaciones clínicas, exámenes de laboratorio e imágenes, si bien pueden orientar el diagnóstico, muchas veces son insuficientes, siendo necesaria la biopsia del tejido afectado. No obstante, en este punto también se plantea una dificultad, si bien, clásicamente se ha descrito que la tuberculosis produce granulomas con necrosis caseificante y la sarcoidosis granulomas no necrotizantes, estos últimos también han sido descritos en la tuberculosis ${ }^{2}$. Esto nos indica, que la histopatología no es específica para discriminar entre ambas enfermedades ${ }^{3,4}$.

La frecuencia relativa de cada enfermedad capaz de producir granulomas va a estar determinada tanto por el tipo de población estudiada como por la epidemiología local. En este sentido, nos pareció importante conocer, a partir de las biopsias de pulmón, pleura y ganglios linfáticos mediastínicos en los que se reportaron granulomas, las características clínicas de los pacientes, los diagnósticos en relación a su frecuencia, tratamiento establecido, respuesta clínica y sobrevida al año de seguimiento. Como objetivo secundario, quisimos intentar identificar si existían diferencias entre las poblaciones con los diagnósticos más habituales.

\section{Material y Métodos}

En forma retrospectiva se analizaron todas las biopsias de pulmón, pleura y ganglios linfáticos mediastínicos procesados en el Servicio de Anatomía Patológica del Instituto Nacional del Tórax que informaban granulomas. El período estudiado se extendió entre los años 2013 y 2016, analizándose las biopsias junto con los antecedentes clínicos y de laboratorio de los respectivos pacientes (sólo se excluyeron 5 casos donde no fue posible obtener la historia clínica) para consignar los siguientes datos:

Datos demográficos: Edad, género y nacionalidad.

Datos clínicos como: Tabaquismo, existencia de algún tipo de inmunosupresión (VIH/ SIDA, mesenquimopatías, inmunosupresión farmacológica, diabetes mellitus, etc.), tiempo de inicio de los síntomas hasta la realización de la biopsia, fiebre (temperatura corporal $>38^{\circ} \mathrm{C}$ ), tos, disnea, sudoración nocturna, baja de peso $>10 \%$, lesiones cutáneas, adenopatías (palpables al examen físico o evidenciadas en exámenes imagenológicos), datos del laboratorio general: Presencia de anemia, leucocitosis y velocidad de eritrosedimentación (VHS), proteína $\mathrm{C}$ reactiva (PCR) alteradas y PPD si fue realizado y $\mathrm{mm}$ de induración calificado como reactivo si era mayor a $5 \mathrm{~mm}$ en pacientes VIH y $10 \mathrm{~mm}$ en población no VIH.

Datos de la histopatología: Lugar de obtención de biopsia, tipo de procedimiento realizado para la biopsia (percutáneo o quirúrgico), tipo de granuloma (necrosis caseosa, necrosis no caseosa o no necrótico), tinción de Ziehl-Neelsen (M. tuberculosis) y Grocott (hongos) realizada a la biopsia.

Datos microbiológicos: Cultivo corriente (en expectoración, lavado broncoalveolar o líquido 
pleural según sitio biopsiado), baciloscopia y cultivo según sitio ${ }^{5}$, PCR (Genexpert para $M$. tuberculosis) ${ }^{6,7}$ y cultivo MGIT (Mycobacteria Growth indicator tube) $)^{8}$ de la biopsia.

Datos de tratamiento: Tratamiento instaurado inicialmente según la sospecha clínica (basado en clínica, exámenes de laboratorio, tipo de granuloma), respuesta a tratamiento (calificada como buena si el paciente resolvía sus síntomas y/o alteraciones de imágenes posterior al tratamiento), diagnóstico final y estatus vital al año de realizada la biopsia obtenido del Registro Civil con causa de fallecimiento.

\section{Análisis estadístico}

Los datos fueron analizados utilizando frecuencias y porcentajes para las variables categóricas, además se utilizaron medias y medianas para evaluar variables continuas. Para el análisis comparativo entre grupos se utilizó $X^{2}$ y test exacto de Fisher. Todo el análisis estadístico se realizó utilizando el software SPSS 16.0 para Windows (SPSS, Chicago, IL, USA). Se definió significancia estadística con un valor $\mathrm{p}<0,05$.

Este estudio fue aprobado para su realización por el Comité Ético-Científico del Servicio de Salud Metropolitano Oriente.

\section{Resultados}

Se analizaron en forma retrospectiva un total de 75 biopsias con diagnóstico de granulomas que fueron procesados en el Servicio de Anatomía Patológica del Instituto Nacional del Tórax. La edad media de estos 75 casos fue de 48,7 \pm 17 (rango 17-94) años, 52\% eran hombres, el 47\% había fumado, el índice paquete/año (IPA) promedio fue $7 \pm 16$. La mayoría de los pacientes eran chilenos y sólo 2 extranjeros (un haitiano y una hindú) ambos con más de 5 años de residencia en Chile. El tiempo de síntomas previo a la realización de la biopsia fue variable, con un promedio de $7 \pm 11$ (0-72) meses (Tabla 1).

De los datos epidemiológicos destaca el antecedente de exposición laboral (sílice o asbesto) en $7(9 \%)$ pacientes. Respecto a las comorbilidades, el 5\% tenía antecedentes de mesenquimopatías y un $23 \%$ de inmunosupresión crónica, estos datos se detallan en la Tabla 1.

Las manifestaciones clínicas más frecuentes fueron tos y disnea, las lesiones cutáneas se presentaron en $6,7 \%$ de los casos, todas descritas como eritema nodoso. De los exámenes de laboratorio, destaca la presencia de anemia en el 33\% de los pacientes. La leucocitosis fue infrecuente
Tabla 1. Características generales de 75 pacientes con granulomas en biopsias del sistema respiratorio

\begin{tabular}{|lr|}
\hline Variable & \\
\hline Edad media (rango), años & $48,7(17-94)$ \\
\hline Género: hombres, n (\%) & $39(52)$ \\
\hline Nacionalidad, n (\%) & $73(97,3$ \\
Chilenos & $2(2,6)$ \\
Extranjeros & \\
Tabaquismo, n (\%) & $13(17,3)$ \\
Fumadores activos & $22(29,3)$ \\
Ex fumadores & $40(53,3)$ \\
Nunca fumadores & $6,9 \pm 16$ \\
\hline Índice paquete año, promedio \pm DE & \\
Exposición laboral, n (\%) & $5(6,7)$ \\
Sílice & $2(2,7)$ \\
Asbesto & \\
\hline Inmunosupresión, n (\%) & \\
VIH & $5(6,7)$ \\
Corticoesteroides & $4(5,3)$ \\
Otros inmunosupresores & $6(8)$ \\
Diabetes mellitus & $2(2,7)$ \\
Mesenquimopatías, n (\%) & \\
Artritis reumatoide & $3(4)$ \\
Síndrome de Sjögren & $1(1,3)$ \\
\hline
\end{tabular}

VIH: Virus de inmunodeficiencia humana.

Tabla 2. Características clínicas de 75 pacientes con granulomas en biopsias del sistema respiratorio

\begin{tabular}{|lr}
\hline Variable & \\
Tiempo de síntomas, \\
promedio \pm DE meses & $7 \pm 11$ \\
Síntomas y signos & $\mathbf{n}(\mathbf{\%})$ \\
Tos & $42(56)$ \\
Disnea & $39(52)$ \\
Fiebre & $22(29)$ \\
Sudoración & $14(18,7)$ \\
Baja de peso & $26(34,7)$ \\
Lesiones cutáneas & $5(6,7)$ \\
Adenopatías & $27(36)$ \\
Exámenes de laboratorio: & $\mathbf{n}(\mathbf{\%})$ \\
Anemia & $25(33,3)$ \\
Leucocitosis & $11(14,7)$ \\
VHS elevada & $32(42)$ \\
PCR elevada & $39(52)$ \\
PPD reactivos (> 10 mm) / & \\
total de realizados & $4 / 12$ \\
\hline
\end{tabular}

VHS: Velocidad de sedimentación eritrocitaria. PCR: Proteína $\mathrm{C}$ reactiva; PPD: Derivado proteico purificado. 
(14\%) y la presencia de índices inflamatorios como velocidad de eritrosedimentación (VHS) y proteína $\mathrm{C}$ reactiva (PCR) elevados, fue un hallazgo común en estos pacientes (Tabla 2).

Las biopsias fueron en su mayoría quirúrgicas $(52 \%)$ todas por videotoracoscopia. Los sitios más frecuentes de biopsia fueron pulmón y luego pleura. La mayoría de los granulomas presentaban necrosis no caseosa (41\%) (Tabla 3).

Respecto a los diagnósticos finales, lo más frecuente fue TBC (49\%), luego Sarcoidosis (24\%). El resto de las patologías tuvo menor frecuencia: Silicosis $(5,3 \%)$, Vasculitis $(4 \%)$ y Neumonitis por Hipersensibilidad (2,7\%). El 4\% de los casos quedó sin diagnóstico (Tabla 4).

De las tinciones realizadas, 4 fueron positivas para la tinción Ziehl-Nielsen. En relación al estudio microbiológico, destaca que se encontraron 5 cultivos MGIT y 7 PCR positivas para M. tuberculosis. En 31 casos una parte de la biopsia fue enviada a cultivo, obteniéndose resultado positivo para M. tuberculosis en 11 casos (36\%) (Tabla 3).

La mayoría de los pacientes estaba vivo al año de seguimiento, con mejoría clínica y/o imagenológica. Sin embargo, 4 pacientes $(5,3 \%)$ fallecieron antes de completar el año de seguimiento: dos de neumonía, uno por hipersensibilidad crónica y uno por TBC (abandono de tratamiento).

\section{Comparación de pacientes con diagnóstico final de tuberculosis versus sarcoidosis}

Dado que los diagnósticos finales más frecuentes fueron TBC y sarcoidosis, se realizó un análisis comparativo de las variables antes mencionadas en ambos grupos diagnósticos.

No se encontraron diferencias significativas en la edad de presentación ni género (pese a existir una mayor frecuencia de hombres en el grupo de tuberculosis, esta diferencia no alcanzó significancia estadística). Lo mismo ocurrió respecto a la nacionalidad, los dos extranjeros tuvieron diagnóstico de tuberculosis, pero no fue estadísticamente significativo. Tampoco hubo diferencias en el tiempo de evolución de los síntomas, tabaquismo, presencia de mesenquimopatías o antecedentes de inmunosupresión.

Respecto al cuadro clínico, se encontraron diferencias significativas en la presencia de lesiones cutáneas, que sólo se presentaron en los pacientes con sarcoidosis y en ninguno con TBC. La presencia de adenopatías también fue más frecuente en la sarcoidosis. Dentro de los exámenes de laboratorio, tanto la VHS como la PCR elevadas fueron significativamente más frecuentes en los pacientes con TBC respecto a los con sarcoidosis.
Tabla 3. Características de las 75 biopsias obtenidas

\begin{tabular}{lr|}
\hline Tipo de biopsia & $\mathbf{n}(\%)$ \\
Videotoracoscopia & $39(52)$ \\
Biopsia transbronquial & $23(30,7)$ \\
Biopsia percutánea & $13(17,3)$ \\
\hline Localización de la biopsia & $\mathbf{n}(\%)$ \\
Pulmón & $40(53,3)$ \\
Pleura & $20(26,7)$ \\
Ganglios de mediastino & $8(10,7)$ \\
Pulmón y pleura & $2(2,7)$ \\
Pulmón y ganglios & $5(6,7)$ \\
Tipo de granulomas & $\mathbf{n}(\%)$ \\
Necrosis caseosa & $21(28)$ \\
Necrosis no caseosa & $31(41)$ \\
No necrotizante & $21(28)$ \\
Tinciones en biopsia & \\
Ziehl-Nielsen, n positivo/total & \\
biopsias analizadas & \\
Grocott, n positivo/ total & \\
biopsias analizadas & \\
Rendimiento del Estudio & \\
Microbiológico para TBC (\%) & \\
Baciloscopia (expectoración o LP & \\
según localización), positiva/ total & \\
de realizadas & \\
Cultivo MGIT expectoración o LP & \\
según localización, positivas/ total & \\
de realizadas & \\
PCR para $M$. tuberculosis, & \\
positivas/ total de realizadas & \\
Cultivo MGIT de biopsia, & \\
n positivas/ total de realizadas & \\
\hline P. & \\
\hline
\end{tabular}

LP: Líquido pleural; MGIT: Mycobacteria Growth Indicator Tube; PCR: Reacción en cadena de la polimerasa.

Tabla 4. Diagnóstico final de 75 pacientes con granulomas en biopsias del sistema respiratorio

\begin{tabular}{|lr|}
\hline Diagnóstico & n (\%) \\
Tuberculosis & $37(49,3)$ \\
Sarcoidosis & $18(24)$ \\
Silicosis & $4(5,3)$ \\
Vasculitis & $3(4)$ \\
Neumonitis por hipersensibilidad & $2(2,7)$ \\
Otros diagnósticos & $7(9,3)$ \\
Sin diagnóstico & $3(4)$ \\
\hline
\end{tabular}

La anemia si bien fue más frecuente en los pacientes con tuberculosis, no alcanzó significancia estadística.

El PPD lamentablemente fue realizado sólo en 12 pacientes, de los cuales 10 eran del grupo 
TBC o sarcoidosis, todos los PPD realizados en los pacientes con sarcoidosis fueron no reactivos y 4 de $6(67 \%)$ realizados en el grupo de TBC fueron reactivos (todos sobre $20 \mathrm{~mm}$ ), los 2 no reactivos eran de pacientes con VIH, estos datos no alcanzan significancia estadística por el escaso número de exámenes realizados (Tabla 5).

Respecto a las biopsias, no existen diferencias en cuanto al método de obtención en relación al diagnóstico final, pero sí según el sitio biopsiado, donde encontramos que las biopsias de pleura presentaban principalmente TBC versus sólo un caso de sarcoidosis. Lo mismo ocurre con los ganglios linfáticos mediastínicos, donde el diagnóstico histológico más frecuente fue sarcoidosis.

En relación al tipo de granuloma, también se encontraron diferencias significativas. Los granulomas con necrosis caseificante fueron más frecuentemente reportados en los casos de TBC (51\%). No se encontró ningún granuloma caseificante en sarcoidosis, donde predominaron granulomas con necrosis no caseificante o sin necrosis (Tabla 6).

\section{Discusión}

En nuestro conocimiento, este estudio es el primer análisis realizado a nivel local de patologías asociadas a la formación de granulomas en pulmón, pleura y ganglios linfáticos mediastínicos. Dentro de los hallazgos más relevantes en nuestra serie de biopsias con granulomas del sistema respiratorio, destaca que la mayoría de nuestros pacientes presentó tuberculosis (49\%), y que la segunda etiología más frecuente fue la sarcoidosis (24\%). Esto es relevante ya que, si bien ambos diagnósticos se presentan con formación de granulomas, el tratamiento de ambas patologías es diferente y hace plantearnos la relevancia de un buen diagnóstico diferencial. No tenemos información de otra serie nacional que analice las biopsias con granulomas del sistema respiratorio en orden de frecuencia de patología detectada, por lo que creemos que la información aportada en este estudio es importante para el clínico a la hora de enfrentarse al resultado de una biopsia con dichas características.

La mayor frecuencia de granulomas de origen tuberculoso en nuestra serie creemos se asocia a la incidencia de TBC en Chile, la cual se encuentra en torno a 14 casos por 100.000 habitantes 9 $\mathrm{Si}$ bien es una cifra baja en comparación con muchos de los países de la región, esta incidencia es mayor que la de países desarrollados como Estados Unidos, cuya incidencia en el año 2014 fue de 3,0 casos por 100.000 habitantes $^{10}$, lo que explica la importante cantidad de casos encontrados. Es necesario aclarar que la mayoría de los casos de TBC en nuestro país actualmente son diagnosticados por métodos bacteriológicos y que en los casos revisados ninguno tuvo bacteriología positiva previa, además, la sospecha diagnóstica en estos casos fue baja dado que la presentación no fue típica ${ }^{5}$. Por otro lado, no tuvimos ningún caso de histoplasmosis, coccidiomiocosis o blastomicosis, enfermedades capaces de producir granulomas pulmonares, pero que no son endémicas de Chile y que han sido descritas en otros países ${ }^{11}$. Tampoco tuvimos casos de aspergilosis pulmonar ni Criptococosis lo que pudiera explicarse por la población estudiada donde la prevalencia de inmunosupresión fue baja.

En el estudio de Mukhopadhyay et al. ${ }^{11}$, se analizaron 500 pacientes de 7 países diferentes y las etiologías más frecuentes encontradas fueron la sarcoidosis y luego infecciones. Destaca la alta frecuencia de etiología indeterminada que llegó al 42\% de los casos, a diferencia de nuestro estudio donde solo tuvimos un $4 \%$ de etiologías no precisadas. Nosotros creemos que esto ocurrió porque incluimos dentro de las variables a analizar la clínica, el estudio microbiológico completo (incluida la PCR para M. tuberculosis) y el seguimiento de los pacientes a un año. En un estudio posterior del mismo autor ${ }^{12}$ realizado sobre biopsias quirúrgicas pulmonares con granulomas necrotizantes en la Clínica Mayo entre 1994 y 2004, de las causas calificadas como "sin etiología histológica" se encontró que la mayoría eran de causa infecciosa, siendo lo más frecuente la histoplasmosis e infecciones por micobacterias no TBC. Esto es concordante con la epidemiología local del estudio, concluyendo que pese a no recibir tratamiento médico en general no habían progresado al seguimiento de 84 meses. Cabe mencionar que, según lo descrito en la literatura, la gran mayoría de las histoplasmosis y una parte importante de las micobacterias no TBC pueden no requerir tratamiento. Esto no es aplicable a nuestra realidad, donde dejar sin tratamiento una infección tuberculosa probablemente lleve a la muerte del paciente.

Pese a que en general la clínica en las enfermedades granulomatosas puede ser inespecífica, y que en nuestro estudio en la mayoría de los síntomas y signos no se encontraron diferencias significativas, es destacable que las lesiones cutáneas (eritema nodoso), sólo fueron reportadas en los casos de sarcoidosis y que la presencia de adenopatías fue significativamente más frecuente en sarcoidosis que en TBC. Respecto a los exámenes generales, la anemia fue más frecuente en 
Tabla 5. Análisis comparativo de las características clínicas de pacientes con granulomas por tuberculosis versus sarcoidosis

\begin{tabular}{|c|c|c|c|}
\hline Variable & $\begin{array}{c}\text { Tuberculosis } \\
\mathbf{n}=\mathbf{3 7}\end{array}$ & $\begin{array}{c}\text { Sarcoidosis } \\
\mathrm{n}=\mathbf{1 8}\end{array}$ & Valor de $\mathbf{p}^{*}$ \\
\hline Edad, mediana (rango) años & $39,5(17-94)$ & $49,5(23-68)$ & 0,13 \\
\hline Edad, media \pm DE años & $45,1 \pm 20,3$ & $49 \pm 13,4$ & \\
\hline Género, hombres n (\%) & $22(59,5)$ & $6(33,3)$ & 0,06 \\
\hline Tabaquismo & & & 0,4 \\
\hline Fumador activo, n (\%) & $7(18,9)$ & $6(33,3)$ & \\
\hline Ex fumador, $\mathrm{n}(\%)$ & $5(13,5)$ & $3(16,7)$ & \\
\hline Nunca fumador, n (\%) & $25(67,6)$ & $9(50)$ & \\
\hline IPA media \pm DE & $21,1 \pm 25$ & $15,3 \pm 21$ & 0,8 \\
\hline \multicolumn{4}{|l|}{ Comorbilidades } \\
\hline Mesenquimopatías, n (\%) & $1(2,7)$ & $2(11,1)$ & 0,19 \\
\hline Inmunosupresión de cualquier causa, n (\%) & $9(24,3)$ & $2(11,1)$ & 0,25 \\
\hline \multicolumn{4}{|l|}{ Cuadro clínico } \\
\hline Tos, n $(\%)$ & $24(64,9)$ & $9(50)$ & 0,21 \\
\hline Disnea, n (\%) & $22(59,5)$ & $9(50)$ & 0,5 \\
\hline Fiebre, n $(\%)$ & $14(37,8)$ & $3(16,7)$ & 0,1 \\
\hline Sudoración, n (\%) & $9(24,3)$ & $3(16,7)$ & 0,5 \\
\hline Baja de peso, n (\%) & $17(49,5)$ & $5(27,8)$ & 0,1 \\
\hline Lesiones cutáneas, n (\%) & $0(0)$ & $4(22,2)$ & $0,003 *$ \\
\hline \multicolumn{4}{|l|}{ Exámenes de laboratorio } \\
\hline Anemia, n (\%) & $15(40,5)$ & $3(16,7)$ & 0,09 \\
\hline Leucocitosis, $\mathrm{n}(\%)$ & $5(13,5)$ & $2(11,1)$ & 0,5 \\
\hline VHS elevada, n (\%) & $22(59,5)$ & $3(16,7)$ & $0,008^{*}$ \\
\hline PCR elevada, n (\%) & $26(70,3)$ & $4(22,2)$ & $0,005^{*}$ \\
\hline PPD reactivo ( $>10 \mathrm{~mm}$ ) / realizados & $4 / 6(66 \%)$ & $0 / 4(0)$ & 0,76 \\
\hline
\end{tabular}

IPA: Índice paquete/año. VHS: Velocidad de sedimentación eritrocitaria; PCR: Proteína C reactiva; *Valor de 'p' calculado por $\chi^{2}$.

Tabla 6. Comparación de biopsias con diagnóstico de TBC versus Sarcoidosis

\begin{tabular}{|c|c|c|c|}
\hline Variable & $\begin{array}{c}\text { Tuberculosis } \\
\mathbf{n}=\mathbf{3 7}\end{array}$ & $\begin{array}{l}\text { Sarcoidosis } \\
n=18\end{array}$ & Valor de $\mathbf{p}^{*}$ \\
\hline $\begin{array}{l}\text { Tipo de biopsia } \\
\text { Quirúrgica (VTC), n (\%) } \\
\text { Biopsia transbronquial, n (\%) } \\
\text { Biopsia percutánea, n }(\%)\end{array}$ & $\begin{array}{r}21(56,8) \\
9(24,3) \\
7(18,9)\end{array}$ & $\begin{array}{l}7(38,9) \\
8(44,4) \\
3(16,7)\end{array}$ & 0,16 \\
\hline $\begin{array}{l}\text { Sitio de biopsia } \\
\text { Pulmón, n (\%) } \\
\text { Pleura, n }(\%) \\
\text { Ganglios, n }(\%) \\
\text { Pulmón y pleura, n }(\%) \\
\text { Pulmón y ganglios, n }(\%)\end{array}$ & $\begin{array}{r}15(40,5) \\
17(45,9) \\
1(2,7) \\
1(2,7) \\
3(8,1)\end{array}$ & $\begin{array}{r}11(61) \\
1(5,5) \\
6(33,3) \\
0(0) \\
0(0)\end{array}$ & $0,001^{*}$ \\
\hline $\begin{array}{l}\text { Tipo de granuloma } \\
\text { Necrótico caseificante, n (\%) } \\
\text { Necrosis no caseificante, n }(\%) \\
\text { No necrotizante, n }(\%)\end{array}$ & $\begin{array}{r}19(51,4) \\
13(35,1) \\
5(13,5)\end{array}$ & $\begin{array}{r}0(0) \\
8(44,4) \\
10(55,6)\end{array}$ & $0,01 *$ \\
\hline
\end{tabular}

VTC: Videotoracoscopia; *Valor de 'p' calculado por $\chi^{2}$.

los pacientes con TBC que en los con sarcoidosis, pero sin alcanzar significación estadística. En relación a los índices inflamatorios, se encontraron diferencias significativas en relación a los valores de VHS y PCR, siendo más altas en los casos de
TBC al compararse con el grupo con sarcoidosis. Todos estos elementos pudieran ser de apoyo al clínico para tomar una decisión en un paciente en particular. El PPD, que lamentablemente fue realizado en muy pocos pacientes, fue no reactivo 
en todos los pacientes con sarcoidosis y reactivo en los pacientes con TBC (excepto 2 pacientes con VIH), dado el escaso número de pacientes con este examen, no es posible sacar conclusiones al respecto y sería interesante de analizar en posteriores estudios.

En la sarcoidosis se han estudiado otros marcadores como la enzima convertidora de angiotensina I (ECA) que es sintetizada por las células epiteliales de los granulomas. Sin embargo, la ECA sérica tiene una utilidad limitada como prueba diagnóstica, debido a la baja sensibilidad (41-57\%) y una especificidad del $90 \%{ }^{13,14}$.

La sarcoidosis es una causa bien conocida de hipercalcemia por hipersecreción de calcitriol, siendo la manifestación más común la hipercalciuria, que se observa en aproximadamente el $30 \%$ de los pacientes, mientras que la hipercalcemia se encuentra en solo 5 a $11 \%{ }^{15,16}$. En cambio, la hipergamaglobulinemia, la cual se observa con frecuencia en pacientes con sarcoidosis, en el estudio de Belhomme et al., no se encontró relación entre el nivel de inmunoglobulina, el diagnóstico y la evolución de la sarcoidosis ${ }^{17}$. En nuestro estudio no se estudiaron estos marcadores y la ECA podría haber aportado en el diagnóstico de sarcoidosis, no obstante, se debe tener en cuenta que este biomarcador puede estar elevado en varias otras enfermedades como la tuberculosis e infecciones fúngicas, entre otras patologías ${ }^{18}$.

En relación al sitio de la biopsia, la TBC fue más frecuente en biopsia de pleura, pero en un caso de sarcoidosis se encontró compromiso pleural, lo cual, si bien es muy infrecuente, está descrito en la literatura ${ }^{11}$. El compromiso ganglionar fue significativamente más frecuente en sarcoidosis.

Respecto al tipo de granuloma, los pacientes del grupo TBC tenían mayoritariamente granulomas con necrosis caseificante, lo que no se encontró en ningún paciente con sarcoidosis donde predominó el granuloma no caseificante y los granulomas no necrotizantes, esto puede ser una importante ayuda en el diagnóstico diferencial ${ }^{19}$.

La silicosis fue la tercera causa de granulomas en las biopsias del sistema respiratorio de nuestra serie. En el diagnóstico diferencial, la búsqueda de partículas de sílice en la muestra histológica, que generalmente son birrefringentes bajo luz polarizada, es $100 \%$ de utilidad y se pueden visualizar a nivel intracelular o extracelular ${ }^{20}$.

Cuando iniciamos nuestro estudio, esperábamos encontrar más pacientes con neumonitis por hipersensibilidad. Sin embargo, solo hubo dos pacientes con este diagnóstico. En relación al diagnóstico de vasculitis, esta se presentó en 4 de estos pacientes. Resultados similares, para estas patologías, fueron reportados por Mukhopadhyay et $\mathrm{al}^{11}$. Del punto de vista del diagnóstico histológico no hay marcadores específicos para neumonitis por hipersensibilidad. Sin embargo, en el lavado bronquioalveolar se puede encontrar un claro predominio linfocitario y una inversión del cociente CD4/CD $8^{21}$. En cuanto al uso de determinaciones inmunológicas y de técnicas de inmunohistoquímica en vasculitis, a diferencia de lo que ocurre en las muestras de riñón, estas no se realizan en pulmón por cuanto no se encuentra estandarizada la forma de procesar la muestra.

Es destacable el buen rendimiento que tuvo el cultivo de los tejidos de las biopsias. En esta serie se intentó aislar $M$. tuberculosis en las muestras de tejido con granulomas, logrando un 35\% de positividad. Si bien, no se analizó dirigidamente si el diagnóstico final de las biopsias negativas fue TBC, nos llama la atención la alta frecuencia de cultivos positivos. Esta observación puede ser relevante, sobre todo considerando el interés actual en relación a la emergencia de cepas de TBC MDR (multidrogo resistente) donde será esencial contar con estudio de susceptibilidad a las drogas ${ }^{9}$, pero esto escapa a la intención de nuestro estudio y podría ser revisado en futuras experiencias.

La información obtenida de esta serie clínica podría llegar a constituir una ayuda para el clínico que se vea enfrentado a una biopsia de este tipo. Por lo cual, se deben considerar una serie de diagnósticos diferenciales expuestos en este estudio.

Si bien nuestro estudio es retrospectivo, lo cual conlleva una serie de posibles sesgos, entre ellos, la dificultad para la obtención de una historia clínica completa en algunos casos, exámenes de laboratorio y la verificación del tratamiento recibido en algunos pacientes, es importante mencionar que en nuestro conocimiento, este estudio realizado en un centro asistencial de referencia nacional, sería por el momento, la única fuente de información local asociada a esta temática y evidenciaría una realidad nacional no descrita previamente.

\section{Conclusiones}

Las enfermedades pulmonares granulomatosas constituyen un importante desafío para los clínicos, principalmente por el amplio abanico de posibles diagnósticos diferenciales. A nuestro entender, nuestra serie sería la primera a nivel nacional que evalúa y diferencia este tipo de biopsias por patología, lo que nos permite acercarnos 
a la frecuencia de los diferentes diagnósticos en nuestra realidad y conocer las características clínicas y microbiológicas de la población estudiada, además del seguimiento, lo que a nuestro parecer aporta datos relevantes para el futuro enfrentamiento y manejo de este tipo de problema diagnóstico.

\section{Bibliografía}

1.- OHSHIMO S, GUZMAN J, COSTABEL U, BONELLA F. Differential diagnosis of granulomatous lung disease: Clues and pitfalls. Eur Respir Rev 2017; 26: 1-16.

2.- MUKHOPADHYAY S, GAL A. Granulomatous Lung Disease. An Approach to the Differential Diagnosis. Arch Pathol Lab Med 2010; 134: 667-90.

3.- JAIN R, MOHAN A, GULERIA R. Sarcoidosis vs tuberculosis: Diagnostic mystery still unresolved. Indian Journal of Tuberculosis 2017; 64: 243-5.

4.- JAIN D, GHOSH S, TEIXEIRA L, MUKHOPADHYAYA S. Pathology of pulmonary tuberculosis and non-tuberculosis mycobacterial lung disease: Facts, misconceptions, and practical tips for pathologists. Semin Diagn Pathol. 2017; 34: 518-29.

5.- LEWINSOHN DM, LEONARD MK, LOBUE PA, COHN DL, DALEY CL, DESMOND E, et al. Official American Thoracic Society/Infectious Diseases Society of America/Centers for Disease Control and Prevention Clinical Practice Guidelines: Diagnosis of Tuberculosis in Adults and Children. Clin Infect Dis. 2017; 64(2): e1-e33.

6.- HORNE DJ, KOHLI M, ZIFODYA JS, SCHILLER I, DENDUKURI N, TOLLEFSON D, et al. Xpert ${ }^{\mathbb{B}}$ MTB/RIF assay for pulmonary tuberculosis and rifampicin resistance in adults. Cochrane Database Syst Rev. 2019 Jun 07; 6: CD009593.

7.- VALLEJO P, RODRÍGUEZ JC, SEARLE A, FARGA V. Ensayo Xpert MTB/RIF en el diagnóstico de tuberculosis. Rev Chil Enferm Respir 2015; 31: 127 31.

8.- PALACI M, UEKI S, SATO N, DA SILVA TELLES M A, CURCIO M, MATHEUS SILVA E A. Evaluation of Mycobacteria Growth Indicator Tube for recovery and drug susceptibility of Mycobacterium tuberculosis isolates from respiratory specimens. J Clin Microbiol 1996; 34: 762-4.

9.- FARGA V, HERRERA T. La tuberculosis en Chile: situación epidemiológica y avances del Programa Nacional de Control y Eliminación 2017. Rev Chil Enferm
Respir 2017; 33: 320-4.

10.- SCOTT C, KIRKING HL, JEFFRIES C, PRICE SF, PRATT R. Tuberculosis trends-United States, 2014. Morb Mortal Wkly Rep 2015; 64: 265-9.

11.- MUKHOPADHYAY S, FARVER C, VASZAR L, DEMPSEY O, POPPER H, MANI H. et al. Causes of pulmonary granulomas: a retrospective study of 500 cases from seven countries. J Clin Pathol 2012; 65: 517.

12.- MUKHOPADHYAY S, WILCOX BE, MYERS JL, BRYANT SC, BUCKWALTER SP, WENGENACK NL, et al. Pulmonary necrotizing granulomas of unknown cause: clinical and pathologic analysis of 131 patients with completely resected nodules. Chest 2013; 144: 813-24.

13.- BAUGHMAN RP, CULVER DA, JUDSON MA. A concise review of pulmonary sarcoidosis. Am J Respir Crit Care Med 2011; 183: 573-81.

14.- UNGPRASERT P, CARMONA EM, CROWSON CS, MATTESON EL. Diagnostic Utility of Angiotensin-Converting Enzyme in Sarcoidosis: A PopulationBased Study. Lung 2016; 194: 91-5.

15.- EKLUND A, DU BOIS RM. Approaches to the treatment of some of the troublesome manifestations of sarcoidosis. J Intern Med 2014; 275: 335-49.

16.- JENY F, BOUVRY D, FREYNET O, SOUSSAN M, BRAUNER M, PLANES C, et al. Management of sarcoidosis in clinical practice. Eur Respir Rev 2016; 25: 141-50.

17. BELHOMME N, JOUNEAU S, BOUZILLÉ G, DECAUX O, LEDERLIN M, GUILLOT S, et al. Role of serum immunoglobulins for predicting sarcoidosis outcome: A cohort study. PLoS One 2018; 13: $\mathrm{e} 0193122$.

18.- LIEBERMAN J, NOSAL A, SCHLESSNER A, SASTRE-FOKEN A. Serum angiotensinconverting enzyme for diagnosis and therapeutic evaluation of sarcoidosis. Am Rev Respir Dis 1979; 120: 329-35.

19.- ROSSI G, CAVAZZA A, COLBY T. Pathology of Sarcoidosis. Clinic Rev Allerg Immunol 2015; 49: 3644.

20.- BANKS DE. The health effects of silica and coal dust exposures. In: Interstitial Lung Disease, 5th, Schwarz MI, King TE Jr (Eds), People's Medical Publishing House, Shelton, CT 2011. p.499.

21.- JARA-PALOMARES L, MARTÍN-JUAN J, GÓMEZ-IZQUIERDO L, CAYUELA-DOMÍNGUEZ A, RODRÍGUEZ-BECERRA E, RODRÍGUEZ-PANADERO F. Hallazgos en el lavado broncoalveolar de pacientes con enfermedad pulmonar intersticial difusa. Estudio de una cohorte prospectiva de 562 pacientes. Arch Bronconeumol. 2009; 45: 111-7.

Correspondencia a:

Dr. Francisco Arancibia Hernández

Instituto Nacional del Tórax, José M. Infante 717, Providencia.

Email: fearancibia@gmail.com 